\title{
Studies on a New Synthetic Route towards Cassiol
}

\author{
M.I. Colombo, J.A. Bacigaluppo, J. Zinczuk, M.P. Mischne and E.A. Rúveda \\ Instituto de Química Orgánica de Síntesis (IQUIOS-UNR), Casilla de Correo 991, 2000 Rosario, Ar- \\ gentina \\ E-mail: ruveda@citynet.net.ar
}

Abstract: The synthesis of the acyclic intermediate 7 towards the preparation of cassiol (2) is described. The cyclization of $\mathbf{7}$ led to $\mathbf{5}$, a precursor of $\mathbf{2}$ and to the unexpected product $\mathbf{8}$.

\section{Introduction}

Cassioside is a glucoside isolated from Cinnamomum cassia Blume which, together with its aglycone, cassiol, are two potent antiulcer agent. The structural features and pharmacological activity of both products have aroused the interest of synthetic organic chemists and several contributions to its synthesis have appeared in the literature in recent years [1,2].

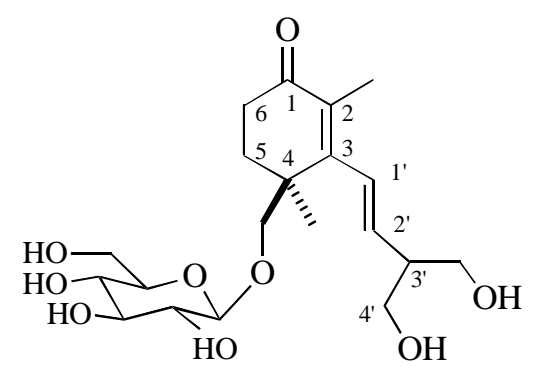

cassioside (1)

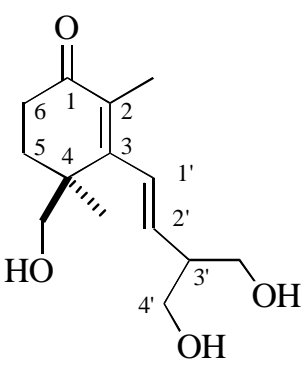

cassiol (2)

We have recently developed a rather simple synthetic sequence for the preparation of $\mathbf{5}$, a precursor of cassiol, by using an olefination reaction of lactol 3 with the 2-benzothiazoleylsulfone 4 , under the conditions reported by S. Julia [3] with a $18 \%$ yield.<smiles>CC1=C2[C@@H](O)OC(=O)C2(C)CCC1=O</smiles>

3<smiles>CCCC1OCC(CS(C)(=O)=O)CO1</smiles>

4<smiles>CCCC1(C)OCC(/C=C/C2=C(C)C(=O)CCC2(C)C(C)=O)CO1</smiles> 
Unfortunately, all our attempts to improve the yield of $\mathbf{5}$ were unsuccessful. A careful analysis of the reaction mixture allowed us the identification of unchanged starting material and some products that suggested that lactol $\mathbf{3}$ would suffer a Canizzaro-type reaction under the olefination reaction conditions, indicating a low reactivity of the carbonyl group of $\mathbf{3}$ under these conditions, probably due to steric hindrance [4].

\section{Discussion and Experimental Part}

In view of the results described above and hoping to prepare $\mathbf{2}$ in better yield, we decided to develop an alternative synthetic sequence, involving a Michael addition followed by an aldol condensation of an open chain substrate like 7.

The preparation of 7, starting with aldehyde 6, was carried out in good overall yield, following the conditions described in Scheme 1.

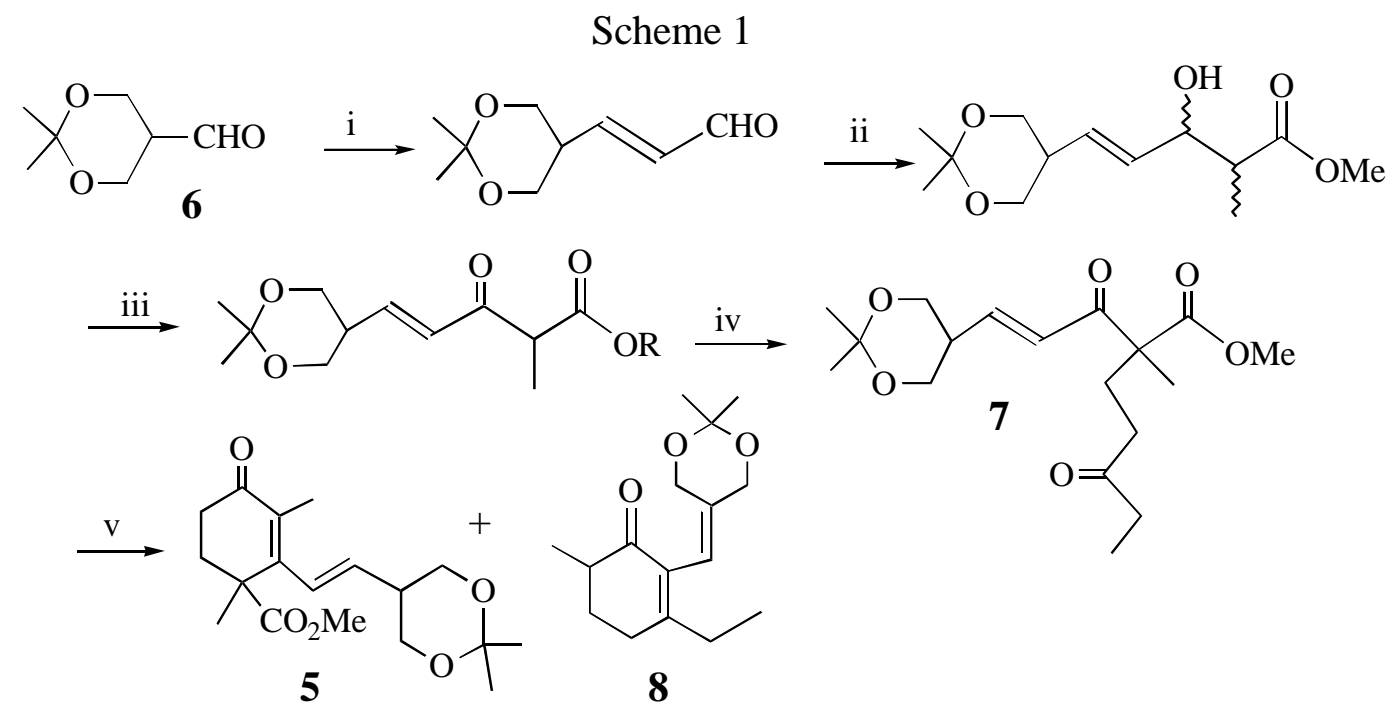

Reagents and conditions: i) (triphenylphosphoranylidene)acetaldehyde, benzene, reflux; ii) methyl propionate, THF, LDA, $-78^{\circ} \mathrm{C}$; iii) $\mathrm{PDC}, \mathrm{CH}_{2} \mathrm{Cl}_{2}, \mathrm{RT}, 24 \mathrm{~h}$; iv) $\left.\mathrm{EVK}, \mathrm{EtOH}, \mathrm{NaOH} ; \mathrm{v}\right) 4 \%$ $\mathrm{KOH}(\mathrm{aq}), \mathrm{MeOH}$, reflux, $7 \mathrm{~h}$.

However, an attempt of cyclization of 7 , with aqueous potassium hydroxide in methanol under reflux, afforded a mixture of $5(10 \%)$ and the unexpected product 8 (60\%). By analyzing the mechanism of formation of $\mathbf{8}$ a new sequence for the synthesis of cassiol (2) will be suggested.

Acknowledgments: We thank Universidad Nacional de Rosario (UNR), Consejo Nacional de Investigaciones Científicas y Técnicas (CONICET) and Agencia Nacional de Promoción Científica y Tecnológica. 


\section{References and Notes}

1. Shiraga, Y.; Okano, K.; Akira, T.; Fukaya, C.; Yokoyama, K.; Tanaka, S.; Fukui, H.; Tabata, M. Tetrahedron 1988, 44, 4703.

2. Colombo, M.I.; Rœveda, E.A. J. Braz. Chem. Soc. 1998, 9, 303.

3. Baudin, J.B.; Hareau, G.; Julia, S.A.; Ruel, O. Tetrahedron Lett. 1991, 32, 1175.

4. Colombo, M.I.; Bacigaluppo, J.A.; Rœveda, E.A. Anales Asoc. Quim. Arg. 1998, 86, 312. 